\title{
Impact of GLUT1 and Ki-67 expression on early-stage lung adenocarcinoma diagnosed according to a new international multidisciplinary classification
}

\author{
YUHO MAKI $^{1}$, JUNICHI SOH ${ }^{1}$, KOUICHI ICHIMURA ${ }^{2}$, KAZUHIKO SHIEN $^{1}$, MASASHI FURUKAWA ${ }^{1}$, \\ TAKAYUKI MURAOKA ${ }^{1}$, NORIMITSU TANAKA ${ }^{1}$, TSUYOSHI UENO ${ }^{1}$, HIROMASA YAMAMOTO ${ }^{1}$, \\ HIROAKI ASANO $^{1}$, KAZUNORI TSUKUDA ${ }^{1}$, SHINICHI TOYOOKA ${ }^{1}$ and SHINICHIRO MIYOSHI ${ }^{1}$
}

Departments of ${ }^{1}$ Thoracic Surgery and ${ }^{2}$ Pathology, Okayama University Hospital, Okayama, Japan

Received July 6, 2012; Accepted September 14, 2012

DOI: 10.3892/or.2012.2087

\begin{abstract}
High expression levels of glucose transporter isoform 1 (GLUT1) and Ki-67 are reportedly associated with malignancy-related clinicopathological factors in malignant tumors. Recently, a new histological IASLC/ATS/ERS classification for lung adenocarcinoma was proposed. In this study, we investigated the clinicopathological impact of GLUT1 and $\mathrm{Ki}-67$ expression on early-stage lung adenocarcinoma classified according to the IASLC/ATS/ERS classification. One hundred and five patients with completely resected stage IA lung adenocarcinoma were retrospectively classified into two groups, a 'non-invasive type' $(n=31)$ or an 'invasive type' $(n=74)$, based on the IASLC/ATS/ERS classification. GLUT1 and Ki-67 expression status was evaluated using immunohistochemistry. The epidermal growth factor receptor (EGFR) and KRAS mutation status was determined using PCR-based assays. Positive GLUT1 and Ki-67 expression and EGFR and KRAS mutations were detected in $28(27 \%)$, $33(31 \%), 51(49 \%)$ and $5(8 \%)$ cases, respectively. Positive GLUT1 expression was significantly associated with a wildtype EGFR and mutant $K R A S$ status. A multivariate analysis revealed that positive GLUT1 expression was independently associated with the 'invasive type'. In multivariate analyses for overall survival (OS) and disease-free survival (DFS), positive Ki-67 and GLUT1 expression was the only independent factor for a poor OS $(\mathrm{P}=0.012)$ and $\mathrm{DFS}(\mathrm{P}=0.040)$, respectively. In addition, when stratified according to the GLUT1 and Ki-67 status, double-positive cases had the poorest DFS and OS times, compared with the other categories. Positive GLUT1 expression is associated with the invasive character of early-
\end{abstract}

Correspondence to: Dr Shinichi Toyooka, Department of Thoracic Surgery, Okayama University Hospital, 2-5-1 Shikata-cho, Kita-ku, Okayama 700-8558, Japan

E-mail: toyooka@md.okayama-u.ac.jp

Key words: early-stage lung adenocarcinoma, glucose transporter isoform 1, Ki-67 stage lung adenocarcinoma and with early disease relapse. Our results strongly suggest that GLUT1 and Ki-67 play important roles in acquiring biological malignant potential in early-stage lung adenocarcinoma.

\section{Introduction}

Lung cancer is the leading cause of cancer-related mortality worldwide $(1,2)$. Lung adenocarcinoma is the most common type of lung cancer, and its incidence has increased in recent years (3). Surgical resection is the treatment of first choice for early-stage lung adenocarcinoma, but the 5-year overall survival (OS) rate remains at $\sim 80 \%$ for stage IA disease (4). Understanding the histological and biological character of early-stage lung adenocarcinoma is important for improving the clinical outcome of this patient population.

Cancer cells often have higher rates of glucose metabolism than normal cells, producing lactic acid rather than catabolizing glucose via the tricarboxylic acid (TCA) cycle (5). The glucose transporter family is a collection of membrane proteins that are responsible for glucose uptake. Glucose transporter isoform 1 (GLUT1) is expressed in the brain and in erythrocytes (6). GLUT1 also maintains a basal level of glucose uptake in most cell types under hypoxic and hypoglycemic conditions. The overexpression of GLUT1 has been observed in many types of human malignancies $(7,8)$. In non-small cell lung cancers (NSCLC), the overexpression of GLUT1 is reportedly associated with a poor prognosis $(9,10)$. As a classical marker of proliferation, the $\mathrm{Ki}-67$ protein is well known to be present in nuclei during the active phase of the cell cycle (11-13), and the overexpression of $\mathrm{Ki}-67$ is a prognostic marker in many types of cancer $(14,15)$. A high Ki-67 labeling index reportedly predicts poor prognosis in stage I NSCLCs (16-19).

Since 2004, the role of activating mutations of epidermal growth factor receptor $(E G F R)$ and $K R A S$ genes as characteristic somatic mutations in lung adenocarcinoma has become a topic of interest, since these mutations exhibit a mutually exclusive relationship and have clinical implications [i.e., $E G F R$ mutations are associated with responsiveness to $E G F R$ tyrosine kinase inhibitors (EGFR-TKIs)] (20-22). 
An international multidisciplinary classification for lung adenocarcinoma was recently proposed by the International Association for the Study of Lung Cancer (IASLC), the American Thoracic Society (ATS), and the European Respiratory Society (ERS) (23). This new classification (the IASLC/ATS/ERS classification) provides uniform terminology and diagnostic criteria especially for adenocarcinoma with lepidic growth which was formerly classified as bronchioloalveolar carcinoma (BAC), as the definition of BAC was unclear in the previous classification (24). The term BAC has been used for a broad spectrum of tumors including solitary small non-invasive peripheral lung tumors, invasive adenocarcinomas with minimal invasion, mixed subtype invasive adenocarcinomas, mucinous and nonmucinous subtypes of tumors and widespread advanced disease; the clinical outcome of patients with BAC has also varied. In the new classification, lung adenocarcinomas are classified into four major categories based on tumor invasiveness: i) preinvasive lesions, ii) minimally invasive adenocarcinoma (MIA), iii) invasive adenocarcinoma, and iv) variants of invasive adenocarcinoma. Invasive adenocarcinoma is the most common type among surgically resected specimens and is subdivided into five types according to semiquantitative subtype patterns, rather than using the term adenocarcinoma, mixed subtype. Notably, patients with preinvasive lesions or MIAs are expected to have a $100 \%$ or nearly $100 \%$ OS following complete resection, suggesting that this new classification may be useful for determining suitable therapeutic strategies and predicting patient outcome.

In this study, we investigated the clinicopathological impact of GLUT1 and Ki-67 expression levels on early-stage lung adenocarcinoma classified according to the IASLC/ATS/ ERS classification.

\section{Materials and methods}

Patients. We reviewed patients with lung adenocarcinoma who had undergone complete resections at Okayama University Hospital between January 2004 and December 2006. A total of 133 consecutive patients with pathologic stage IA disease, according to the International Union Against Cancer's TNM classification for malignant tumors (25), underwent complete tumor resection. Among them, patients with recurrent tumor or second primary lung adenocarcinoma were excluded. As a result, 105 patients with stage IA lung adenocarcinoma were eligible for this study. The follow-up protocol after surgery was as follows: chest and abdominal computed tomography (CT) or positron emission tomography/CT scan and enhanced brain magnetic resonance imaging were repeated every six months for three years. After three years, a chest X-ray was, in principle, repeated ever year and additional examinations were performed as necessary.

Histological classification and immunohistochemistry for GLUT1 and Ki-67. Two investigators (K.I. and Y.M.) who were unaware of the clinical data independently classified all the tumors according to the IASLC/ATS/ERS classification and discussed the final diagnosis in cases with diagnostic discrepancies. The written informed consent of each patient and the permission of the Institutional Review Board were obtained. This study was approved by the Ethics Committee of Okayama University (approval no. 478).

For the immunohistochemistry (IHC), 4- $\mu \mathrm{m}$ sections were cut from paraffin-embedded tissue specimens on MAS-GP type A coated glass slides (S-9901; Matsunami Glass Ind., Ltd., Osaka, Japan). The slides were deparaffinized in xylene and rehydrated in a graded series of ethanol (100, 100, 90, 70 and $50 \%$ ). After revealing antigens with $10 \mathrm{mM}$ of sodium citrate $(\mathrm{pH} 6.0)$, the slides were incubated in $3 \% \mathrm{H}_{2} \mathrm{O}_{2}$ for 10 min to block endogenous peroxidase. To inhibit non-specific binding, the samples were incubated in diluted normal horse serum for $30 \mathrm{~min}$. After blocking, the slides were incubated with GLUT1 (Abcam, Cambridge, UK; diluted 1:200 in PBS) and Ki-67 (Novocastra, Newcastle, UK; diluted 1:2,000 in PBS) antibodies at $4^{\circ} \mathrm{C}$ overnight. The slides were washed in PBS for $5 \mathrm{~min}$ and incubated in secondary antibody for $30 \mathrm{~min}$ at room temperature (ImmPRESS Anti-Rabbit Ig peroxidase Polymer Detection kit; Vector Laboratories, Peterborough, UK). The slides were stained with 3,3'-diaminobenzidine (DAB Substrate kit; Vector Laboratories), and were counterstained in Mayer's hematoxylin. Tumor cells were considered positive for GLUT1 if the cell membrane staining was no less than that of the erythrocytes in the same section. GLUT1 expression was considered positive in each section if the percentage of tumor cells with positive staining was $>10 \%$, as previously reported (7,26,27). Ki-67 staining was evaluated using the labeling index $(28,29)$. In the area with the strongest Ki-67 staining, positively stained cells were defined as having a clearly stained nucleus and the Ki-67 labeling index was considered positive when $>15 \%$ of the tumor cells were stained among at least 1,000 tumor cells (30-32).

DNA extraction and mutation analyses of EGFR and KRAS genes. DNA was extracted from formalin-fixed and paraffinembedded tissues $(n=51)$ or frozen tissues $(n=54)$ using the QIAamp ${ }^{\circledR}$ DNA FFPE Tissue kit (Qiagen, Hilden, Germany) or by digestion with proteinase $\mathrm{K}$, followed by phenol-chloroform (1:1) extraction and ethanol precipitation, respectively. EGFR mutational status was determined using a mutant non-enriched PCR assay, as previously reported (33). KRAS mutations at codons 12 and 13 were examined using PCR-based direct sequencing using an ABI PRISM 3130xl Genetic Analyzer (Applied Biosystems, Foster City, CA, USA), as previously reported $(34,35)$.

Statistical analysis. Differences between the two groups were assessed using $\chi^{2}$ tests or Fisher's exact test, as appropriate. Multiple logistic regression analyses were used to identify independent factors and to adjust for the influence of other co-variables. The OS and disease-free survival (DFS) periods were calculated from the date of operation until the date of death or the last follow-up for the OS and until confirmed disease recurrence based on cross-sectional imaging studies or death for the DFS.

A univariate analysis of the OS and DFS was performed using the Kaplan-Meier method and the log-rank test. A multivariate analysis for OS and DFS was performed using the Cox proportional-hazards model. The stepwise procedure was used to select independent variables using a backward elimination method with P-values of 0.10 for entry and 0.15 for rejection. 
Table I. Patient characteristics.

\begin{tabular}{|c|c|c|}
\hline Subsets & $\mathrm{n}$ & $\%$ \\
\hline \multicolumn{3}{|l|}{ Age } \\
\hline$<65$ & 52 & 49.5 \\
\hline$\geq 65$ & 53 & 50.5 \\
\hline \multicolumn{3}{|l|}{ Gender } \\
\hline Male & 49 & 46.7 \\
\hline Female & 56 & 53.3 \\
\hline \multicolumn{3}{|l|}{ Smoking status } \\
\hline Never & 56 & 53.3 \\
\hline Ever & 49 & 46.7 \\
\hline \multicolumn{3}{|l|}{ Tumor size } \\
\hline T1a $(\leq 2 \mathrm{~cm})$ & 73 & 69.5 \\
\hline $\mathrm{T} 1 \mathrm{~b}(>2 \mathrm{~cm})$ & 32 & 30.5 \\
\hline \multicolumn{3}{|l|}{ GLUT1 expression } \\
\hline Negative & 77 & 73.3 \\
\hline Positive & 28 & 26.7 \\
\hline \multicolumn{3}{|l|}{ Ki-67 expression } \\
\hline Negative & 72 & 68.6 \\
\hline Positive & 33 & 31.4 \\
\hline \multicolumn{3}{|l|}{$E G F R$ mutation } \\
\hline Mutant & 51 & 48.6 \\
\hline Wild-type & 54 & 51.4 \\
\hline \multicolumn{3}{|l|}{ KRAS mutation } \\
\hline Mutant & 5 & 4.8 \\
\hline Wild-type & 100 & 95.2 \\
\hline \multicolumn{3}{|l|}{$\begin{array}{l}\text { IASLC/ATS/ERS classification } \\
\text { Preinvasive lesion }\end{array}$} \\
\hline \multicolumn{3}{|l|}{ Adenocarcinoma in situ } \\
\hline Nonmucinous & 19 & 18.1 \\
\hline Mucinous & 0 & 0.0 \\
\hline Mixed mucinous/nonmucinous & 0 & 0.0 \\
\hline \multicolumn{3}{|l|}{ Minimally invasive adenocarcinoma } \\
\hline Nonmucinous & 12 & 11.4 \\
\hline Mucinous & 0 & 0.0 \\
\hline Mixed mucinous/nonmucinous & 0 & 0.0 \\
\hline \multicolumn{3}{|l|}{ Invasive adenocarcinoma } \\
\hline Lepidic predominant & 18 & 17.1 \\
\hline Acinar predominant & 1 & 1.0 \\
\hline Papillary predominant & 45 & 42.9 \\
\hline Micropapillary predominant & 0 & 0.0 \\
\hline Solid predominant with mucin production & 5 & 4.8 \\
\hline \multicolumn{3}{|l|}{ Variants of invasive adenocarcinoma } \\
\hline Invasive mucinous adenocarcinoma & 5 & 4.8 \\
\hline Colloid & 0 & 0.0 \\
\hline Fetal & 0 & 0.0 \\
\hline Enteric & 0 & 0.0 \\
\hline
\end{tabular}

GLUT1, glucose transporter isoform 1; EGFR, epidermal growth factor receptor.
All the data were analyzed using the JMP, version 9.0.0 (SAS Institute Inc., Cary, NC, USA).

\section{Results}

Patient characteristics. The patient characteristics are shown in Table I. The median age was 65 years (range, 29-83 years); 49 patients were men, and 56 were women. The smoking categories were defined as follows: never-smokers, those with a lifetime exposure of $\leq 100$ cigarettes; and ever-smokers, those with a lifetime exposure of $>100$ cigarettes. Eighty-eight patients underwent a lobectomy, while a segmentectomy or wedge resection was performed for 17 tumors exhibiting a pure ground glass opacity during CT imaging. We defined these cases as curative operations since none of the 17 cases experienced disease relapse.

IASLC/ATS/ERS classification of lung adenocarcinoma. The details of the lung adenocarcinoma subtypes according to the IASLC/ATS/ERS classification are shown in Table I. Among the four categories, invasive adenocarcinoma $(n=69$, $65.7 \%$ ) was the most frequent diagnosis in this study. Among the invasive adenocarcinomas, $63.8 \%$ would have been diagnosed as mixed subtype, according to the 2004 World Health Organization classification (24). Since adenocarcinoma in situ (AIS) and minimally invasive adenocarcinoma (MIA) with a diameter equal to $2 \mathrm{~cm}$ or less have previously been reported to have a 5-year OS or DFS rate of $100 \%(36,37)$, we defined these tumors as 'non-invasive type' $(n=31)$ and compared them with the other 'invasive type' $(n=74)$ adenocarcinomas, including invasive adenocarcinoma and invasive mucinous adenocarcinoma. We then performed further analyses comparing those two groups.

Molecular alterations in clinical samples. The results and representative samples of the IHC staining patterns for GLUT1 and Ki-67 are shown in Table II and Fig. 1. Positive GLUT1 and Ki-67 expressions were observed in 28 (26.7\%) and 33 (31.4\%) of the 105 patients, respectively. Among the 105 tumors, we detected EGFR mutations in 51 tumors (48.6\%). Mutations in KRAS codons 12 or 13 were detected in 5 of the 105 tumors $(8.3 \%)$.

The inter-relationships of GLUT1 and Ki-67 expression levels and EGFR and KRAS mutations were examined. Positive GLUT1 expression was significantly more common among $E G F R$ wild-type cases $(\mathrm{P}=0.004), K R A S$ mutant cases $(\mathrm{P}=0.02)$, and tumors with positive Ki-67 expression $(\mathrm{P}=0.003)$ (Table II).

Relationship between molecular alterations and clinicopathological factors. The associations between the above-mentioned molecular alterations and clinical factors are shown in Table II. Positive GLUT1 expression was significantly more common among men $(\mathrm{P}<0.001)$, ever smokers $(\mathrm{P}=0.008)$, and patients with large tumors (T1b) $(\mathrm{P}=0.009)$. Positive Ki-67 expression was significantly more common among men $(\mathrm{P}<0.001)$ and ever smokers $(\mathrm{P}=0.005)$. Mutant $E G F R$ was significantly more common among women $(\mathrm{P}<0.001)$ and never smokers $(\mathrm{P}=0.002)$. Mutant $K R A S$ was not significantly associated with any clinical factor. 
Table II. GLUT1 and Ki-67 expression and clinical and genetic factors.

\begin{tabular}{|c|c|c|c|c|c|c|c|c|c|c|c|c|}
\hline \multirow[b]{2}{*}{ Subsets } & \multicolumn{3}{|c|}{ GLUT1 positive } & \multicolumn{3}{|c|}{$\mathrm{Ki}-67$ positive } & \multicolumn{3}{|c|}{$E G F R$ mutant } & \multicolumn{3}{|c|}{ KRAS mutant } \\
\hline & $\mathrm{n}$ & $\%$ & $\mathrm{P}$-value & $\mathrm{n}$ & $\%$ & P-value & $\mathrm{n}$ & $\%$ & P-value & $\mathrm{n}$ & $\%$ & P-value \\
\hline \multicolumn{13}{|l|}{ Age } \\
\hline$<65$ & 14 & 26.9 & 1 & 14 & 26.9 & 0.3 & 23 & 44.2 & 0.8 & 1 & 1.9 & 0.2 \\
\hline$\geq 65$ & 14 & 26.4 & & 19 & 35.8 & & 28 & 52.8 & & 4 & 7.5 & \\
\hline \multicolumn{13}{|l|}{ Gender } \\
\hline Male & 21 & 42.9 & $<0.001$ & 24 & 49.0 & $<0.001$ & 15 & 30.6 & $<0.001$ & 2 & 4.1 & 0.8 \\
\hline Female & 7 & 12.5 & & 9 & 16.1 & & 36 & 64.3 & & 3 & 5.4 & \\
\hline \multicolumn{13}{|l|}{ Smoking status } \\
\hline Never & 9 & 16.1 & 0.008 & 11 & 19.6 & 0.005 & 35 & 62.5 & 0.002 & 2 & 3.6 & 0.4 \\
\hline Ever & 19 & 38.8 & & 22 & 44.9 & & 16 & 32.7 & & 3 & 6.1 & \\
\hline \multicolumn{13}{|l|}{ Tumor size } \\
\hline $\mathrm{T} 1 \mathrm{a}(\leq 2 \mathrm{~cm})$ & 14 & 19.2 & 0.009 & 21 & 28.8 & 0.4 & 32 & 43.8 & 0.14 & 3 & 4.1 & 0.2 \\
\hline $\mathrm{T} 1 \mathrm{~b}(>2 \mathrm{~cm})$ & 14 & 43.8 & & 12 & 37.5 & & 19 & 59.4 & & 2 & 6.3 & \\
\hline \multicolumn{13}{|c|}{ GLUT1 expression } \\
\hline Negative & - & - & - & 18 & 23.4 & 0.003 & 44 & 57.1 & 0.004 & 1 & 1.3 & 0.02 \\
\hline Positive & - & - & & 15 & 53.6 & & 7 & 25.0 & & 4 & 14.3 & \\
\hline \multicolumn{13}{|c|}{ Ki-67 expression } \\
\hline Negative & 13 & 18.1 & 0.003 & - & - & - & 38 & 52.8 & 0.2 & 2 & 2.8 & 0.2 \\
\hline Positive & 15 & 45.5 & & - & - & & 13 & 39.4 & & 3 & 9.1 & \\
\hline \multicolumn{13}{|c|}{$E G F R$ mutation } \\
\hline Mutant & 7 & 13.7 & 0.004 & 20 & 37.0 & 0.2 & - & - & - & 0 & 0.0 & 0.03 \\
\hline Wild-type & 21 & 38.9 & & 13 & 25.5 & & - & - & & 5 & 9.8 & \\
\hline \multicolumn{13}{|l|}{$K R A S$ mutation } \\
\hline Mutant & 4 & 80.0 & 0.02 & 3 & 60.0 & 0.2 & 0 & 0.0 & 0.03 & - & - & - \\
\hline Wild-type & 24 & 24.0 & & 30 & 30.0 & & 51 & 51.0 & & - & - & \\
\hline
\end{tabular}

GLUT1, glucose transporter isoform 1; EGFR, epidermal growth factor receptor.
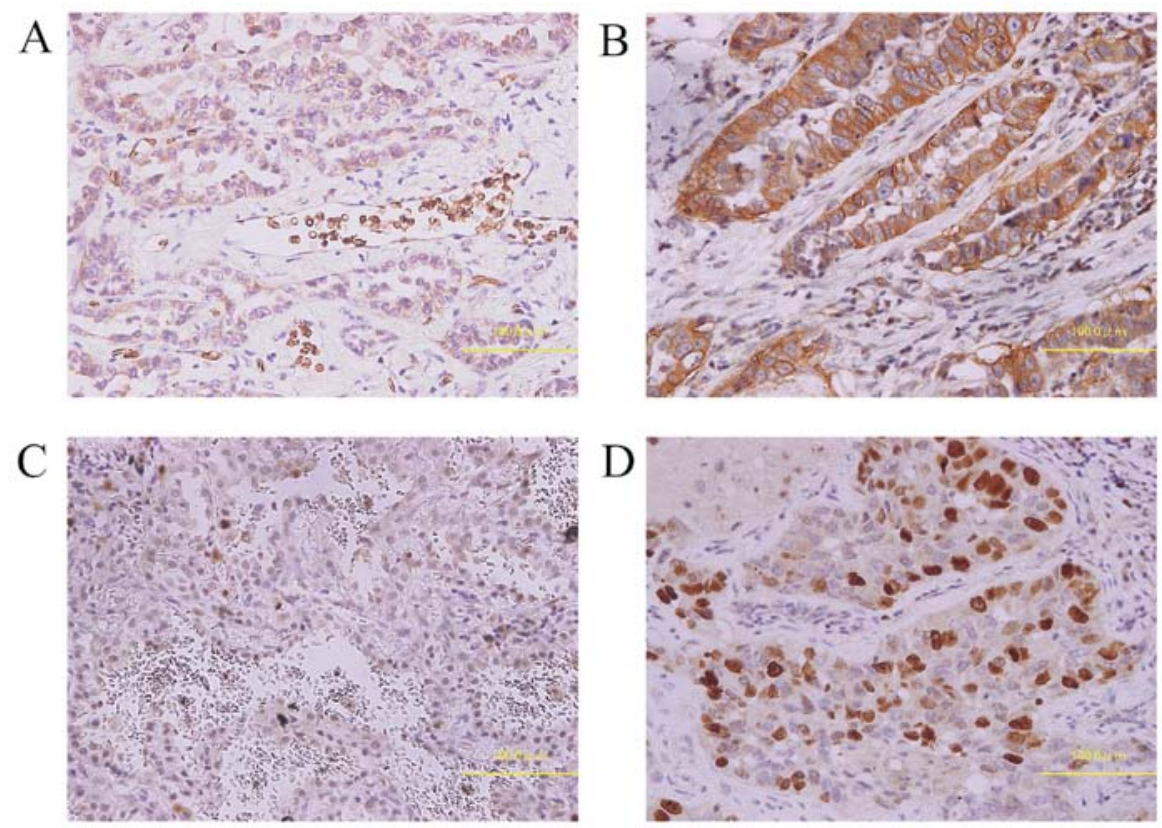

Figure 1. Representative results of immunohistochemistry for GLUT1 and Ki-67. (A) Negative staining for GLUT1. Erythrocytes were used as an internal positive control. (B) Positive staining for GLUT1. (C) Negative staining for Ki-67 (labeling index, 2.0\%). (D) Positive staining for Ki-67 (labeling index, $29.2 \%$ ). 
Table III. Association between 'invasive type' adenocarcinoma and clinical and genetic factors.

\begin{tabular}{|c|c|c|c|c|}
\hline \multirow[b]{2}{*}{ Subsets } & \multirow[b]{2}{*}{$\mathrm{n}$} & \multirow[b]{2}{*}{$\%$} & \multirow{2}{*}{$\frac{\text { Univariate }}{\text { P-value }}$} & \multirow{2}{*}{$\frac{\text { Multivariat }}{\text { P-value }}$} \\
\hline & & & & \\
\hline \multicolumn{5}{|l|}{ Age } \\
\hline$<65$ & 37 & 71.2 & 0.9 & \\
\hline$\geq 65$ & 37 & 69.8 & & \\
\hline \multicolumn{5}{|l|}{ Gender } \\
\hline Male & 37 & 75.5 & 0.3 & \\
\hline Female & 37 & 66.1 & & \\
\hline \multicolumn{5}{|l|}{ Smoking status } \\
\hline Never & 36 & 64.3 & 0.14 & \\
\hline Ever & 38 & 77.6 & & \\
\hline \multicolumn{5}{|l|}{ Tumor size } \\
\hline $\mathrm{T} 1 \mathrm{a}(\leq 2 \mathrm{~cm})$ & 46 & 63.0 & 0.01 & 0.06 \\
\hline $\mathrm{T} 1 \mathrm{~b}(>2 \mathrm{~cm})$ & 28 & 87.5 & & \\
\hline \multicolumn{5}{|c|}{ GLUT1 expression } \\
\hline Negative & 48 & 62.3 & 0.002 & 0.048 \\
\hline Positive & 26 & 92.9 & & \\
\hline \multicolumn{5}{|c|}{ Ki-67 expression } \\
\hline Negative & 45 & 62.5 & 0.01 & 0.06 \\
\hline Positive & 29 & 87.9 & & \\
\hline \multicolumn{5}{|c|}{$E G F R$ mutation } \\
\hline Mutant & 39 & 76.5 & 0.19 & \\
\hline Wild-type & 35 & 64.8 & & \\
\hline \multicolumn{5}{|l|}{$K R A S$ mutation } \\
\hline Mutant & 4 & 80.0 & 1.0 & \\
\hline Wild-type & 70 & 70.0 & & \\
\hline
\end{tabular}

GLUT1, glucose transporter isoform 1; EGFR, epidermal growth factor receptor.

Furthermore, we investigated the relationship between the IASLC/ATS/ERS classification and clinical and molecular factors (Table III). 'Invasive type' adenocarcinomas were more common among patients with large tumors $(\mathrm{P}=0.01)$, GLUT1 positive tumors $(\mathrm{P}=0.002)$, and Ki-67 positive tumors $(\mathrm{P}=0.01)$. In a multiple logistic regression analysis including the significant factors mentioned above, 'invasive type' adenocarcinomas were only correlated with positive GLUT1 expression [odds ratio (OR), 4.85; 95\% confidence interval (CI), 1.21-32.56; $\mathrm{P}=0.048]$.

Impact of GLUT1 and Ki-67 expression on clinical outcome. As of September 2011, 4 (3.8\%) of the 105 patients had succumbed and the median follow-up duration was 59.7 months. Ten (9.5\%) patients had experienced disease relapse. The 5-year OS rate was $94.6 \%$ (95\% CI, 86.0-98.0\%). The 5-year DFS rate was 90.2\% (95\% CI, 81.9-94.8\%). The associations between OS or DFS and clinicopathological and genetic factors are shown in Table IV. The associations between the OS and clinicopathological and genetic factors

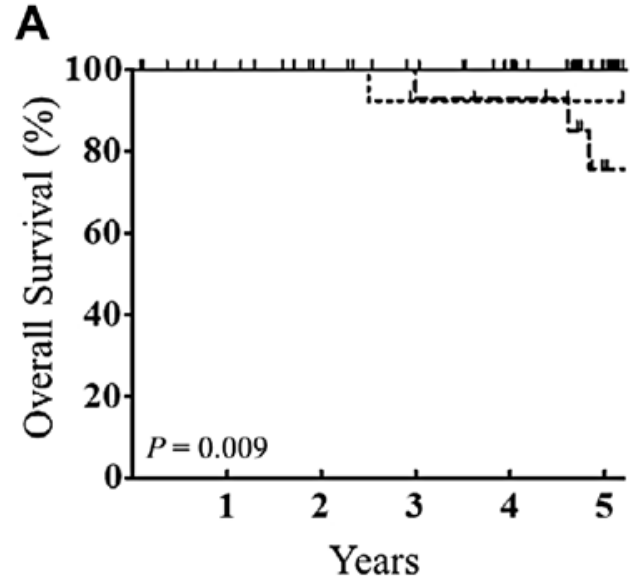

B

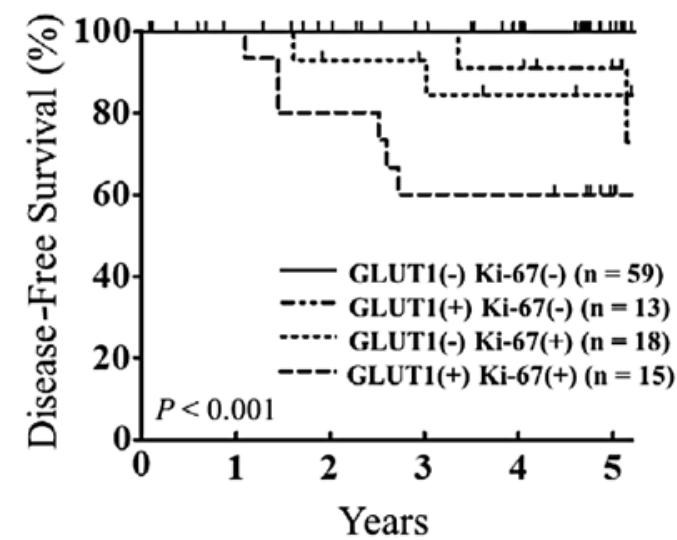

Figure 2. Kaplan-Meier plots of survival rates according to GLUT1 and Ki-67 expressions. (A) Overall survival of all patients. (B) Disease free survival of all patients. The resulting curves were compared using a log-rank test.

showed that positive $\mathrm{Ki}-67$ expression was the only significant factor of a poor OS $(\mathrm{P}=0.002)$, although positive GLUT1 expression and 'invasive type' adenocarcinoma tended to be correlated with a poor OS $(\mathrm{P}=0.063$ and $\mathrm{P}=0.098$, respectively) according to univariate analysis. In a multivariate analysis, Ki-67 was the only independent factor associated with a poor OS [hazard ratio (HR), $2.0 \times 10^{7} ; 95 \%$ CI, 2.00$\left.3.27 \times 10^{59} ; \mathrm{P}=0.012\right]$. All 10 tumors in patients with disease relapse were diagnosed as 'invasive type' adenocarcinomas. In univariate analyses, a male gender $(\mathrm{P}=0.02)$, an ever smoking status $(\mathrm{P}=0.02)$, an 'invasive type' classification $(\mathrm{P}=0.005)$, a positive GLUT1 expression ( $\mathrm{P}=0.0003)$, and a positive Ki-67 expression $(\mathrm{P}=0.0005)$ were significantly associated with a poor DFS. In a multivariate analysis including the significant factors mentioned above, positive GLUT1 expression was the only independent predictor of a poor DFS (HR, 6.02; 95\% CI, 1.25-48.22; $\mathrm{P}=0.040$ ), although positive $\mathrm{Ki}-67$ expression tended to correlate with a poor DFS (HR, 6.49; $95 \%$ CI, 1.1557.53; $\mathrm{P}=0.058)$.

We also investigated the impact of the combined effect of GLUT1 and Ki-67 expression on OS and DFS. We found that patients with positive expression for both GLUT1 and Ki-67 had a poorer clinical outcome than the other patients (OS, $\mathrm{P}=0.009$ and $\mathrm{DFS}, \mathrm{P}<0.0001$ ) (Fig. 2). 
Table IV. Cox proportional hazards model for post-operative overall survival and disease-free survival.

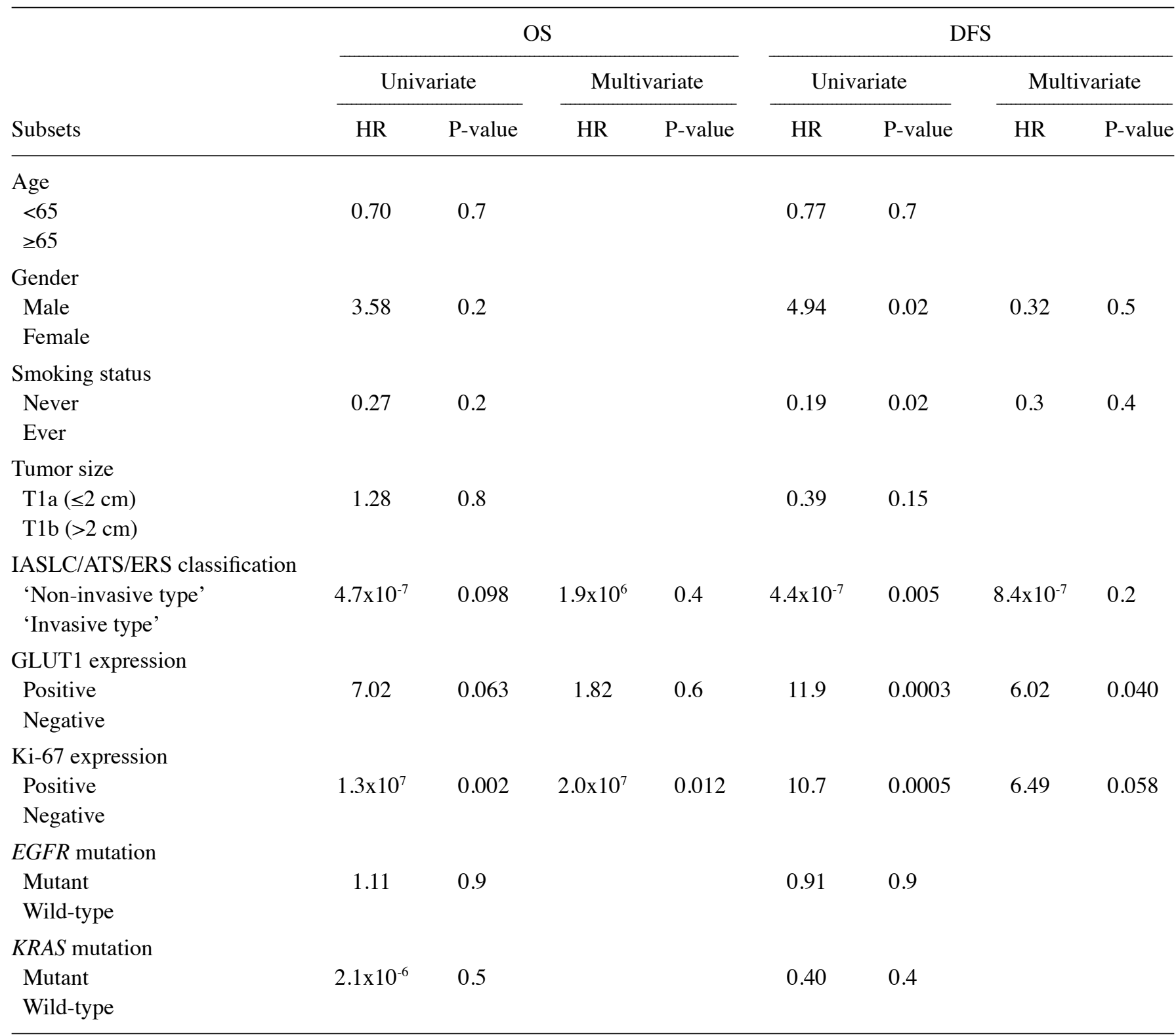

OS, overall survival; DFS, disease-free survival; HR, hazard ratio; 95\% CI, 95\% confidence interval; GLUT1, glucose transporter isoform 1; EGFR, epidermal growth factor receptor.

\section{Discussion}

In this study, we investigated the expression status of GLUT1 and Ki-67 in early-stage cases of lung adenocarcinoma classified according to a new international multidisciplinary classification, the IASLC/ATS/ERS classification, and found that, i) positive GLUT1 expression was significantly associated with a wild-type $E G F R$ and mutant $K R A S$ status, ii) GLUT1 expression was independently associated with 'invasive type' adenocarcinomas, and iii) positive GLUT1 expression was correlated with positive Ki-67 expression and double positive expression was associated with a poor outcome.

We examined the EGFR and KRAS mutations, which are key somatic mutations of lung adenocarcinoma, in the patient population and analyzed the correlations between the mutation status and GLUT1 expression, Ki-67 expression, and histolog- ical features. The frequent overexpression of GLUT1 in NSCLC has been reported in patients with wild-type EGFR and mutant $K R A S$ (38). In the present study, we found that positive GLUT1 expression was frequently observed in lung adenocarcinomas without EGFR mutation and in those with KRAS mutation. Although the association between the GLUT1 expression level and the initiation of these mutations is unknown, low glucose environments, which promote GLUT1 expression, have been reported as a driving force underlying the development of KRAS mutations during colorectal tumorigenesis (39).

Both GLUT1 and Ki-67 are known to be associated with tumor invasiveness and proliferation (40). Moreover, Noguchi et al (41) reported that small lung adenocarcinomas (with a diameter equal to $2 \mathrm{~cm}$ or less) with pure or minimally invasive 'BAC' (Noguchi types A and B) had a 5-year DFS of $100 \%$ after complete resection as confirmed by subsequent 
reports $(42,43)$. The IASLC/ATS/ERS classification has also indicated that patients with AIS or MIA have a $100 \%$ or nearly $100 \%$ DFS. In this study, we classified AIS and MIA as "noninvasive type' adenocarcinomas and compared them with 'invasive type' adenocarcinomas; as a result, positive GLUT1 expression was found to be the only independent factor associated with 'invasive' adenocarcinoma. High expression levels of GLUT1 have previously been reported as a significant predictor of a poor outcome in 47 cases of stage IA and IB adenocarcinoma (16). In the present study, we demonstrated that GLUT1 and $\mathrm{Ki}-67$ were the most significant factors associated with a poor clinical outcome with regard to the DFS and OS, respectively. Of interest, GLUT1 and Ki-67 double-positive cases had the poorest DFS and OS time, suggesting that this population exhibited a high degree of biological malignancy. These findings also suggest that these markers may be useful for predicting the recurrence of disease after the complete resection of early-stage lung adenocarcinoma and may be useful for the selection of patients requiring adjuvant therapy.

In conclusion, positive GLUT1 expression is frequently observed in 'invasive type' early-stage lung adenocarcinoma, as classified according to the IASLC/ATS/ERS classification. Our results strongly suggest that GLUT1, together with Ki-67, plays an important role in the acquisition of biological malignant potential in early-stage lung adenocarcinoma.

\section{Acknowledgements}

The authors thank Ayako Isobe (General Thoracic, Breast and Endocrinological Surgery, Okayama University Graduate School of Medicine) for preparing the pathological materials. The authors also thank the Central Research Laboratory, Okayama University Medical School, for their technical support with the immunohistochemical staining.

\section{References}

1. Ferlay J, Shin HR, Bray F, Forman D, Mathers C and Parkin DM Estimates of worldwide burden of cancer in 2008: GLOBOCAN 2008. Int J Cancer 127: 2893-2917, 2010.

2. Jemal A, Bray F, Center MM, Ferlay J, Ward E and Forman D: Global cancer statistics. CA Cancer J Clin 61: 69-90, 2011.

3. Devesa SS, Bray F, Vizcaino AP and Parkin DM: International lung cancer trends by histologic type: male:female differences diminishing and adenocarcinoma rates rising. Int $\mathbf{J}$ Cancer 117: 294-299, 2005

4. van Rens MT, de la Riviere AB, Elbers HR and van Den Bosch JM: Prognostic assessment of 2,361 patients who underwent pulmonary resection for non-small cell lung cancer, stage I, II, and IIIA. Chest 117: 374-379, 2000.

5. Koike T, Kimura N, Miyazaki K, et al: Hypoxia induces adhesion molecules on cancer cells: A missing link between Warburg effect and induction of selectin-ligand carbohydrates. Proc Natl Acad Sci USA 101: 8132-8137, 2004.

6. Wood IS and Trayhurn P: Glucose transporters (GLUT and SGLT): expanded families of sugar transport proteins. Br J Nutr 89: 3-9, 2003.

7. Kalir T, Wang BY, Goldfischer M, et al: Immunohistochemical staining of GLUT1 in benign, borderline, and malignant ovarian epithelia. Cancer 94: 1078-1082, 2002.

8. Carvalho KC, Cunha IW, Rocha RM, et al: GLUT1 expression in malignant tumors and its use as an immunodiagnostic marker Clinics (São Paulo) 66: 965-972, 2011.

9. Koukourakis MI, Giatromanolaki A, Bougioukas G and Sivridis E: Lung cancer: a comparative study of metabolism related protein expression in cancer cells and tumor associated stroma. Cancer Biol Ther 6: 1476-1479, 2007.
10. Wang K, Sun Y and Wang T: The prognostic significance of GLUT1 expression in stage I and II NSCLC. Zhongguo Fei Ai Za Zhi 5: 451-453, 2002 (In Chinese).

11. Brown DC and Gatter KC: Ki67 protein: the immaculate deception? Histopathology 40: 2-11, 2002.

12. Jalava P, Kuopio T, Juntti-Patinen L, Kotkansalo T, Kronqvist $P$ and Collan Y: Ki67 immunohistochemistry: a valuable marker in prognostication but with a risk of misclassification: proliferation subgroups formed based on Ki67 immunoreactivity and standardized mitotic index. Histopathology 48: 674-682, 2006.

13. Scholzen T and Gerdes J: The Ki-67 protein: from the known and the unknown. J Cell Physiol 182: 311-322, 2000.

14. Goldhirsch A, Ingle JN, Gelber RD, Coates AS, Thurlimann B and Senn HJ: Thresholds for therapies: highlights of the St Gallen International Expert Consensus on the primary therapy of early breast cancer 2009. Ann Oncol 20: 1319-1329, 2009.

15. Klintman M, Bendahl PO, Grabau D, Lovgren K, Malmstrom P and Ferno M: The prognostic value of Ki67 is dependent on estrogen receptor status and histological grade in premenopausal patients with node-negative breast cancer. Mod Pathol 23: 251-259, 2010.

16. Minami K, Saito Y, Imamura $\mathrm{H}$ and Okamura A: Prognostic significance of p53, Ki-67, VEGF and Glut-1 in resected stage I adenocarcinoma of the lung. Lung Cancer 38: 51-57, 2002.

17. Tungekar MF, Gatter KC, Dunnill MS and Mason DY: Ki-67 immunostaining and survival in operable lung cancer. Histopathology 19: 545-550, 1991.

18. Simony J, Pujol JL, Radal M, Ursule E, Michel FB and Pujol H: In situ evaluation of growth fraction determined by monoclonal antibody $\mathrm{Ki}-67$ and ploidy in surgically resected non-small cell lung cancers. Cancer Res 50: 4382-4387, 1990.

19. Mehdi SA, Etzell JE, Newman NB, Weidner N, Kohman LJ and Graziano SL: Prognostic significance of Ki-67 immunostaining and symptoms in resected stage I and II non-small cell lung cancer. Lung Cancer 20: 99-108, 1998.

20. Cappuzzo F, Hirsch FR, Rossi E, et al: Epidermal growth factor receptor gene and protein and gefitinib sensitivity in non-smallcell lung cancer. J Natl Cancer Inst 97: 643-655, 2005.

21. Ichihara S, Toyooka S, Fujiwara Y, et al: The impact of epidermal growth factor receptor gene status on gefitinib-treated Japanese patients with non-small-cell lung cancer. Int J Cancer 120: 1239-1247, 2007.

22. Toyooka S, Mitsudomi T, Soh J, et al: Molecular oncology of lung cancer. Gen Thorac Cardiovasc Surg 59: 527-537, 2011.

23. Travis WD, Brambilla E, Noguchi M, et al: International association for the study of lung cancer/american thoracic society/ european respiratory society international multidisciplinary classification of lung adenocarcinoma. J Thorac Oncol 6: 244-285, 2011.

24. Travis WD, Brambilla E, Muller-Hermelink HK and Harris CC (eds): World Health Organization Classification of Tumours Pathology and genetics of tumours of the lung, pleura, thymus and heart. IARC Press, Lyon, 2004.

25. Rami-Porta R, Crowley JJ and Goldstraw P: The revised TNM staging system for lung cancer. Ann Thorac Cardiovasc Surg 15: 4-9, 2009.

26. Jun YJ, Jang SM, Han HL, Lee KH, Jang KS and Paik SS: Clinicopathologic significance of GLUT1 expression and its correlation with Apaf-1 in colorectal adenocarcinomas. World J Gastroenterol 17: 1866-1873, 2011.

27. Parente P, Coli A, Massi G, Mangoni A, Fabrizi MM and Bigotti G: Immunohistochemical expression of the glucose transporters Glut-1 and Glut-3 in human malignant melanomas and benign melanocytic lesions. J Exp Clin Cancer Res 27: 34, 2008.

28. Yerushalmi R, Woods R, Ravdin PM, Hayes MM and Gelmon KA: Ki67 in breast cancer: prognostic and predictive potential. Lancet Oncol 11: 174-183, 2010.

29. Dowsett M, Nielsen TO, A'Hern R, et al: Assessment of Ki67 in Breast Cancer: recommendations from the international Ki67 in Breast Cancer working group. J Natl Cancer Inst 103: 1656-1664, 2011.

30. Goldhirsch A, Wood WC, Coates AS, Gelber RD, Thurlimann B and Senn HJ: Strategies for subtypes - dealing with the diversity of breast cancer: highlights of the St. Gallen International Expert Consensus on the Primary Therapy of Early Breast Cancer 2011. Ann Oncol 22: 1736-1747, 2011.

31. Colozza M, Sidoni A and Piccart-Gebhart M: Value of Ki67 in breast cancer: the debate is still open. Lancet Oncol 11: 414-415, 2010. 
32. Jonat $\mathrm{W}$ and Arnold $\mathrm{N}$ : Is the $\mathrm{Ki}-67$ labelling index ready for clinical use? Ann Oncol 22: 500-502, 2011.

33. Asano H, Toyooka S, Tokumo M, et al: Detection of EGFR gene mutation in lung cancer by mutant-enriched polymerase chain reaction assay. Clin Cancer Res 12: 43-48, 2006.

34. Tokumo M, Toyooka S, Kiura K, et al: The relationship between epidermal growth factor receptor mutations and clinicopathologic features in non-small cell lung cancers. Clin Cancer Res 11: $1167-1173,2005$.

35. Suehisa H, Toyooka S, Hotta K, et al: Epidermal growth factor receptor mutation status and adjuvant chemotherapy with uracil-tegafur for adenocarcinoma of the lung. J Clin Oncol 25: 3952-3957, 2007.

36. Watanabe S, Watanabe T, Arai K, Kasai T, Haratake J and Urayama H: Results of wedge resection for focal bronchioloalveolar carcinoma showing pure ground-glass attenuation on computed tomography. Ann Thorac Surg 73: 1071-1075, 2002.

37. Yamada S and Kohno T: Video-assisted thoracic surgery for pure ground-glass opacities $2 \mathrm{~cm}$ or less in diameter. Ann Thorac Surg 77: 1911-1915, 2004.
38. Sasaki H, Shitara M, Yokota K, et al: Overexpression of GLUT1 correlates with Kras mutations in lung carcinomas. Mol Med Rep 5: 599-602, 2012.

39. Yun J, Rago C, Cheong I, et al: Glucose deprivation contributes to the development of KRAS pathway mutations in tumor cells. Science 325: 1555-1559, 2009.

40. Furudoi A, Tanaka S, Haruma K, et al: Clinical significance of human erythrocyte glucose transporter 1 expression at the deepest invasive site of advanced colorectal carcinoma. Oncology 60: 162-169, 2001

41. Noguchi M, Morikawa A, Kawasaki M, et al: Small adenocarcinoma of the lung. Histologic characteristics and prognosis. Cancer 75: 2844-2852, 1995.

42. Yokose T, Suzuki K, Nagai K, Nishiwaki Y, Sasaki S and Ochiai A: Favorable and unfavorable morphological prognostic factors in peripheral adenocarcinoma of the lung $3 \mathrm{~cm}$ or less in diameter. Lung Cancer 29: 179-188, 2000.

43. Yoshida J, Nagai K, Yokose T, et al: Limited resection trial for pulmonary ground-glass opacity nodules: fifty-case experience. J Thorac Cardiovasc Surg 129: 991-996, 2005. 